QA: QA

Civilian Radioactive Waste Management System

Management \& Operating Contractor

\author{
Performance Confirmation Plan
}

TDR-PCS-SE-000001 REV 01 ICN 01

\author{
May 2000
}

Prepared for:

U.S. Department of Energy

Yucca Mountain Site Characterization Office

P.O. Box 30307

North Las Vegas, Nevada 89036-0307

Prepared by:

TRW Environmental Safety Systems Inc.

1211 Town Center Drive

Las Vegas, Nevada 89144

Under Contract Number

DE-AC08-91RW00134 


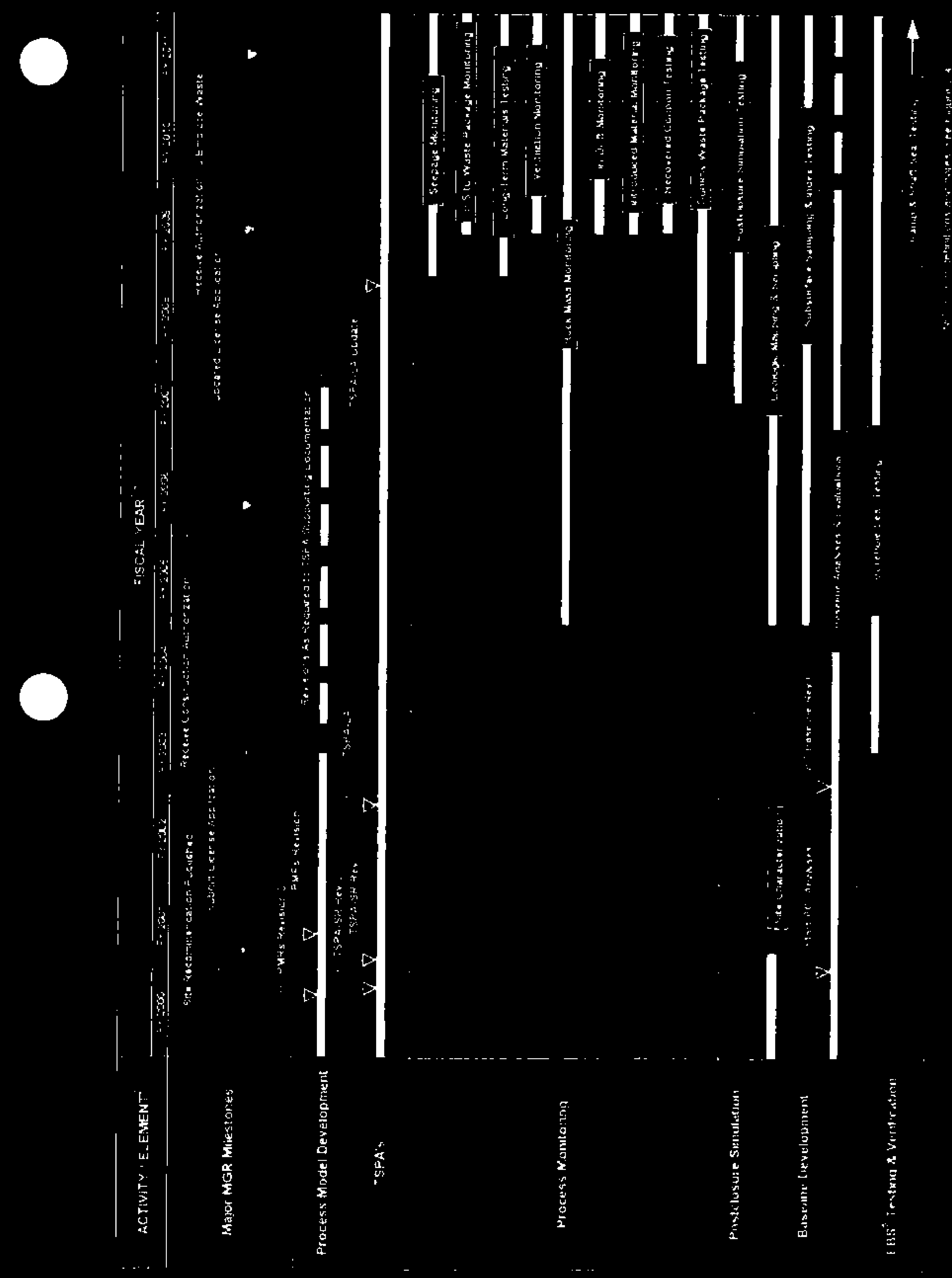




\subsubsection{Specific Process Modeling for Preclosure Analyses}

\subsubsection{General}

Establishment of the baseline for the Performance Confirmation Plan involves interpolating and extrapolating site parameter values measured at discrete points, such as in surface-based boreholes, the Exploratory Studies Facility (ESF), and the Cross Drift, to obtain values for the entire potential repository horizon. These interpolations and extrapolations may be accomplished by simple arithmetic calculations, by calibration of mathematical process models, and by inverse process modeling. The process models used in the evaluation are described in Section 3.3 and the key performance confirmation factors that require testing are described in Section 3.4.2.

All testing conducted under the performance confirmation program will require pre-test predictions, including predictions for tests to be performed for baseline purposes. To illustrate the types of modeling that may be required to predict baseline conditions that will be confirmed, the following sections focus on the predictions associated with performance confirmation factors derived from the RSS as described in Section 3.4.2. Additional baseline predictions beyond the types identified here will be required if TSPA sensitivities indicate that the potential performance confirmation factors derived from the preliminary PMR data needs (Section 3.4.3) remain in the program, or if other factors are identified prior to the LA submittal for inclusion in the program because of their postclosure safety significance. For this version of the Performance Confirmation Plan, the specific modeling and prediction discussions to follow are provided for illustrative purposes only.

\subsubsection{Unsaturated Zone Flow and Transport}

The primary performance confirmation factor for the UZ flow and transport is ambient flow through the repository horizon and seepage into unventilated drifts. Existing UZ flow and transport models, built upon and calibrated against a wealth of site characterization data, contain both pre- and postclosure predictions of the performance of the UZ, specifically with regard to percolation flux and seepage into unventilated drifts. These models can be utilized to conduct performance confirmation baseline modeling of the planned performance confirmation testing and monitoring as described in Section 5.3. The testing outcomes will be used to compare with UZ flow and transport model predictions.

\subsubsection{Waste Form Degradation}

Currently ongoing laboratory testing will continue to completion during construction of the underground facility. For Zircaloy-clad CSNF, the release is controlled by the cladding failure rate after waste package failure. For this reason, there is the potential of long-term testing of Zircaloy if the data available at the time of the LA proves inadequate to justify the cladding model. The release of neptunium-237 from the failed waste package is controlled by its solubility in the water in the transport pathway. Whether the pathway is diffusion or advection dominated depends on the degree of failure of the waste package (i.e., diffusion out of small openings as opposed to flow through larger openings). For this reason, there is a potential data 
- Interactions with the NRC and stakeholder organizations.

\subsubsection{Corrective Action Implementation}

The implementation of the corrective actions will be the responsibility of the following organizations:

- YMP Téchnical database: Technical Data Management Department

- Conceptual and mathematical process models and associated computer codes, depending on process: Applied Research and Testing Department, Repository Design Section, Waste Package Design Section, Waste Package Materials Section, Engineered Barrier System Department

- TSPA mathematical model and computer software: Performance Assessment Department

- Performance confirmation program coordination: Systems Engineering Department

- Performance confirmation test facilities and support system design: Systems Engineering Department, Engineered Barrier System Department

- MGR design: Systems Engineering Department, Waste Package Design Section, Waste Package Materials Section, Engineered Barrier System Department, Surface Facilities Department

- Performance confirmation test facilities, support system, and repository construction and operation, including waste emplacement and retrieval: Site Construction Department

- Interactions with the NRC and stakeholder organizations: Regulatory and Licensing Department

- File abandonment or MGR closure: Site Construction Department and Regulatory and Licensing Department.

In addition, Systems Engineering Department has the responsibility to monitor the implementation of these changes and to revise the Performance Confirmation Plan accordingly.

\subsubsection{Baseline Change Control}

Baseline change control will assure that the above changes are baselined and controlled in accordance with QA procedures to ensure that the same up-to-date data and information will be used by personnel for activities described under evaluations and corrective actions, including the implementation of the corrective actions. Baseline and change control will cover:

- Performance confirmation data

- Technical, process and TSPA, computer codes

- Monitoring and testing plans and specifications 
Identified in the present version of the MGR-PDD (CRWMS M\&O 2000d) are performance criteria and several assumptions that, although not directly attributed to performance confirmation, represent current design assumptions that affect performance confirmation activities. Specific performance criteria, which affect the performance of the performance confirmation program, are listed in Table E-5; specific controlled assumptions that affect the performance of the performance confirmation program are listed in Table E-6. Both tables present a brief discussion of applicability of the items identified to the Performance Confirmation Plan.

Table E-1. Performance Confirmation Requirements Based on MGR-RD ${ }^{1}$

\begin{tabular}{|c|c|}
\hline Reference & Requirement and Assessment \\
\hline $\begin{array}{c}\text { Section } 3.1 \\
\text { Regulatory } \\
\text { Requirements } \\
\text { Item } 3.1 \mathrm{C}\end{array}$ & $\begin{array}{l}\text { Requirement": } \\
\text { "The MGR shall comply with the interim guidance entitled, "Revised Interim Guidance } \\
\text { Pending Issuance of New U.S. Nuclear Regulatory Commission (NRC) Regulations (Revision } \\
\text { O1, July 22, 1999) for Yucca Mountain, Nevada" (Dyer 1999), developed to reflect the } \\
\text { proposed NRC and U.S. Environmental Protection Agency (EPA) regulatory requirements. } \\
{\left[C R D^{2} 3.1 .1 . C\right]^{\prime}} \\
\text { Assessment: } \\
\text { This interim guidance makes direct reference to performance confirmation, and it is } \\
\text { considered in more detail in Table E-2. Subpart } \mathrm{F} \text { of this interim guidance specifies } \\
\text { performance confirmation activities, together with the definition of performance confirmation } \\
\text { under Subpart A, and performance confirmation design requirements under Subpart } \mathrm{E} \text {. }\end{array}$ \\
\hline Item 3.1G & $\begin{array}{l}\text { Requirement: } \\
\text { "In addition to meeting the primary requirements identified above, the MGR shall comply with } \\
\text { other laws, statutes, U.S. Codes, treaties, CFRs, Executive Orders, NUREGs, state and local } \\
\text { codes and regulations, DOE Orders, and other directives applicable to the geologic disposal } \\
\text { of SNF and HLW, including those related to environmental protection and radiological health } \\
\text { and safety, as identified through analyses of the MGR. [CRD 2.4.JJICRD 3.2.2.CI" } \\
\text { Assessment: } \\
\text { At this time, no other document in this category was identified as directly applicable to } \\
\text { performance confirmation. }\end{array}$ \\
\hline
\end{tabular}


activities will occur only in the event of a waste package failure (which is not a planned event). Further, if a malfunction event did occur, the needed facilities and equipment appropriate for the test would need to be identified and procured, significantly delaying the start of the test process.

\section{Period of Performance/Schedule}

This activity is not a scheduled test or analysis. However, a schedule for the subsurface and surface facility operations for this testing will be developed at the time a malfunction is observed. 